\title{
Abuso físico infantil: vivências e atitudes de estudantes de Odontologia
}

\author{
Priscila Thaís Rodrigues de Abreu*; Isabela Faria de Souza Costa*; Amanda Galvão*; Ana Carla de \\ Paula Souza*; Keli Bahia Felicíssimo Zocratto**; Camilla Aparecida Silva de Oliveira***
}

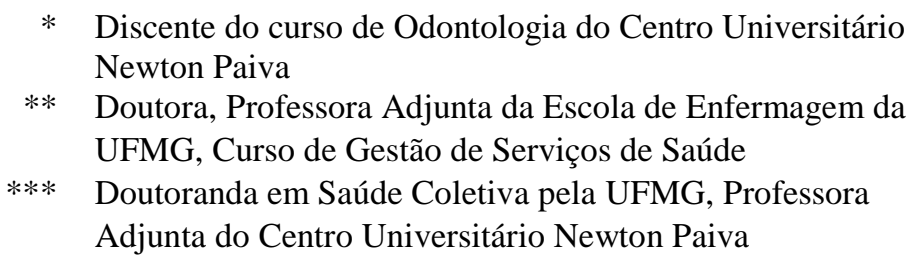

Recebido em 26/01/2017. Aprovado em 04/05/2017.

\begin{abstract}
RESUMO
O objetivo desse estudo foi verificar as vivências e as atitudes dos graduandos em Odontologia frente a casos de abuso físico infantil. O estudo foi realizado no ano de 2016, com uma amostra representativa $(\mathrm{n}=195)$ de alunos do $6^{\circ}$ ao $9^{\circ}$ período de uma instituição de ensino privada. Os dados foram coletados por meio de questionário autoaplicável validado para a língua portuguesa. $\mathrm{Na}$ análise estatística realizaram-se análises descritiva e comparativa com os testes Qui-quadrado, Kruskal-Wallis e comparações múltiplas. A maioria dos alunos não identificou casos de abuso físico infantil $(85,6 \%)$, não realizou notificações $(97,4 \%)$ e julga saber o órgão ao qual notificar $(74,4 \%)$, sendo citado o Conselho Tutelar $(65,0 \%)$. Em uma escala de 0 a 10 , a graduação tem colaborado com uma média de 5,47 no preparo do aluno para o atendimento à criança vítima de abuso. Nesse sentido, 89,7\% dos alunos declararam interesse em receber treinamentos sobre o tema. Observou-se diferença significativa entre os períodos no que se refere à efetividade de reconhecer os principais sinais e sintomas do abuso físico infantil e interesse em treinamentos sobre o tema. Com base nos resultados sugere-se a necessidade de maior ênfase no tema durante o curso, visando o preparo do futuro profissional para atuar frente a casos de abuso físico infantil.
\end{abstract}

Descritores: Maus-tratos Infantis. Odontologia. Estudantes.

\section{INTRODUÇÃO}

O abuso físico infantil (AFI) é definido como o uso intencional da força física contra uma criança, que resulte em danos reais ou potenciais à sua saúde, sobrevivência, desenvolvimento ou dignidade ${ }^{1}$. Segundo dados da Organização Mundial da Saúde, estima-se que cerca de $23 \%$ das crianças em todo o mundo sofreram AFI em 2014². Nas grandes cidades brasileiras a agressão é considerada a primeira causa externa responsável pelos óbitos na faixa etária de 0 a $19 \operatorname{anos}^{3}$. Estima-se que nos 
últimos 15 anos a prevalência de AFI no Brasil foi de aproximadamente $15,7 \%{ }^{4}$. As principais organizações governamentais e não governamentais estão sensibilizadas quanto ao debate da violência infantil, visto tratar-se de um problema de saúde pública ${ }^{5}$.

$\mathrm{Na}$ maioria dos casos, o AFI é cometido dentro do próprio lar, caracterizando a violência doméstica $^{6}$. Dentre as injúrias associadas aos maus-tratos, evidenciam-se as lesões orofaciais, presentes em cerca de 50 a $70 \%$ dos casos $^{7}$. Destacam-se as contusões, desvios da abertura bucal, lacerações, queimaduras provocadas por alimentos quentes ou utensílios domésticos, equimoses nas bochechas sugerindo agressão por socos ou tapas, bem como a presença de escaras no canto da boca devido ao amordaçamento $^{8,9}$.

Como visto, uma gama de lesões pode acometer a face, colocando o cirurgião-dentista em posição estratégica para identificar os casos e realizar a notificação compulsória $(\mathrm{NC})^{10,12}$. Segundo a Constituição Federal e o Estatuto Brasileiro da Criança e do Adolescente é dever legal, ético e moral de qualquer profissional da saúde notificar às autoridades quaisquer casos suspeitos de $\mathrm{AFI}^{3}$. O Conselho Federal de Odontologia explicita no código deontológico que é dever do cirurgião-dentista zelar pela saúde e dignidade do paciente ${ }^{12,14}$. Tais fatos justificam a necessidade da abordagem do assunto durante a graduação ${ }^{15,16}$.

A abordagem adequada é de suma importância para a formação do estudante, pois capacitará o futuro profissional a diagnosticar e adotar condutas assertivas frente a possíveis casos de $\mathrm{AFI}^{16}$. Estudos apontam que a abordagem do tema durante a graduação não tem ocorrido de forma satisfatória, o que pode repercutir em uma futura formação inadequada e deficiente nesse quesito ${ }^{17}$. Portanto, faz-se necessário avaliar a experiência dos alunos acerca do tema a fim de elaborar melhoras curriculares e projetos de intervenção pedagógica, no intuito de conscientizar o egresso quanto à importância do problema ${ }^{18,19}$.

$O$ uso de um instrumento de coleta validado é necessário para que se avalie a experiência dos alunos que cursam Odontologia, bem como os cirurgiões-dentistas, frente a casos de AFI. Contudo, há uma escassez de estudos que utilizem questionários validados e adaptados ao idioma local ${ }^{9,16,23}$. Nesse sentido, essa pesquisa teve como objetivo verificar as vivências e as atitudes dos estudantes do curso de Odontologia de uma instituição de ensino privada, frente a casos de AFI, por meio da utilização de um questionário validado em português, comparando os resultados de acordo com o período do curso em andamento.

\section{MATERIAL E MÉTODOS}

Trata-se de um estudo de caráter transversal, realizado no ano de 2016 em uma instituição de ensino privada, no Município de Belo Horizonte/MG. O universo do estudo foi composto por 365 alunos do $6^{\circ}$ ao $9^{\circ}$ período do curso de Odontologia, uma vez que nesta etapa do curso já possuem contato com o público infantil nas clínicas de Odontopediatria.

Para esse estudo realizou-se cálculo amostral pelo método de estimativa de proporções populacionais finita, considerando uma prevalência de $53 \%$ para identificação do $\mathrm{AFI}^{24}$, nível de confiança de $95 \%$ e significância de 5\%. Obteve-se uma amostra mínima de 188 alunos e, no intuito de resguardar a precisão, aumentou-se a amostra em 20\%, a fim de compensar eventuais perdas, obtendo-se uma amostra final de 226 alunos.

Os alunos foram selecionados de forma aleatória, por sorteio, mantendo-se a propor- 
cionalidade para cada período do curso. A abordagem dos pesquisados foi realizada em sala de aula, em horários cedidos pelos professores. Aqueles que aceitaram participar assinaram o termo de consentimento livre e esclarecido e posteriormente receberam o questionário.

O questionário semiestruturado e autoaplicável utilizado nessa pesquisa foi originalmente desenvolvido por Lazenbatti e Freeman $(2006)^{11}$ e posteriomente traduzido, adaptado transculturalmente e validado no Brasil por Silva-Oliveira et al. $(2014)^{24}$. Para o presente estudo, pequenas adaptações foram realizadas no questionário a fim de adequá-lo ao público-alvo, sem comprometimento do seu conteúdo e entendimento.

As questões abordaram dados do entrevistado (idade, gênero e período do curso); detecção e NC de qualquer suspeita e/ou casos confirmados do AFI; barreiras para a NC, autoavaliação sobre a capacidade de reconhecer e diagnosticar o AFI, bem como perguntas sobre a formação e o interesse em relação ao atendimento à criança. As questões de autoavaliação foram mensuradas por meio de uma escala, com valor mínimo de zero (incapacidade de identificar/ indisposto) e valor máximo de 10 (capacidade total de identificação/ totalmente disposto) ${ }^{24}$.

Os dados obtidos foram analisados meio da distribuição de frequências, medidas de tendência central e variabilidade. $O$ teste de Kolmogorov-Smirnov foi utilizado para avaliar a normalidade das variáveis quantitativas. Como apresentaram distribuição não gaussiana, o teste não-paramétrico do Qui-quadrado foi utilizado para avaliar as variáveis dicotômicas e o teste de Kruskal-Wallis para comparar as variáveis ordinais (escalas de 0 a 10) segundo o período do curso $\left(6^{\circ}, 7^{\circ}, 8^{\circ}\right.$ e $\left.9^{\circ}\right)$. Realizaram-se comparações múltiplas para determinar quais grupos eram diferentes (family-wise error rate FWER). O nível de significância estatística adotado foi de 5\%. Utilizaram-se os softwares Statiscal Package for the Social Sciences (SPSS) versão 19.0 e Action Stat versão 3.1.

$\mathrm{O}$ presente estudo foi submetido à apreciação do Comitê de Ética e aprovado sob o CAAE 55515616.0.0000.5097.

\section{RESULTADOS}

No total, 195 (86,2\%) alunos responderam ao questionário. Destes, $142(72,8 \%)$ eram do gênero feminino, $46(23,6 \%)$ do masculino e 7 $(3,6 \%)$ que não relataram seu gênero. $A$ idade variou de 20 a 44 anos, com média de 24,42 $( \pm 4,5)$. Observou-se que $58(29,7 \%)$ alunos encontravam-se no $6^{\circ}$ período, $55(28,2 \%)$ no $7^{\circ}, 41(21,0 \%)$ no $8^{\circ}$ e $41(21,0 \%)$ no $9^{\circ}$.

Durante a graduação, apenas 28 (14,4\%) alunos relataram ter presenciado casos suspeitos de AFI entre seus pacientes. Destes, a maioria $(85,6 \%)$ relatou haver visto apenas um caso. Somente $6(3,1 \%)$ identificaram casos que envolviam trauma orofacial. A NC foi realizada apenas por $5(2,6 \%)$ alunos. No último ano, 43 $(22,1 \%)$ alunos se depararam com casos suspeitos de AFI e 20 (10,3\%), eram casos comprovados. Desses, apenas 4 (2,1\%) notificaram às autoridades. A maioria dos alunos $(175,89,7 \%)$ expressa interesse em receber treinamentos sobre mecanismos de identificação e NC de casos de AFI e acredita que estes devam fazer parte dos cursos de capacitação profissional, 189 (96,6\%) (tabela 1).

Ao comparar as atitudes e experiências dos alunos de Odontologia conforme o período do curso, observou-se que houve diferença estatisticamente significativa $(\mathrm{p}<0,05)$ para a pergunta: "Você quer receber treinamento sobre como identificar e sobre os mecanismos 
de notificação de casos suspeitos de abuso físico em crianças?", apontando que o interesse dos estudantes do $6^{\circ}, 7^{\circ}$ e $9^{\circ}$ períodos foi 1,2 vezes superior ao do $8^{\circ}$ período. Não houve diferenças estatísticas entre os períodos para as demais perguntas (tabela 2).

No total, $145(74,4 \%)$ alunos responderam saber o órgão ou a instituição a qual recorrer para notificar casos suspeitos de AFI. O gráfico 1 evidencia quais os principais órgãos ou instituições citados pelos alunos. Ressalta-se que cada aluno pôde citar mais de uma opção, por isso, $41(28,2 \%)$ recorreriam a mais de um órgão ou instituição.
Gráfico 1 - Principais órgãos e instituições aos quais os estudantes notificariam casos suspeitos de abuso físico infantil.

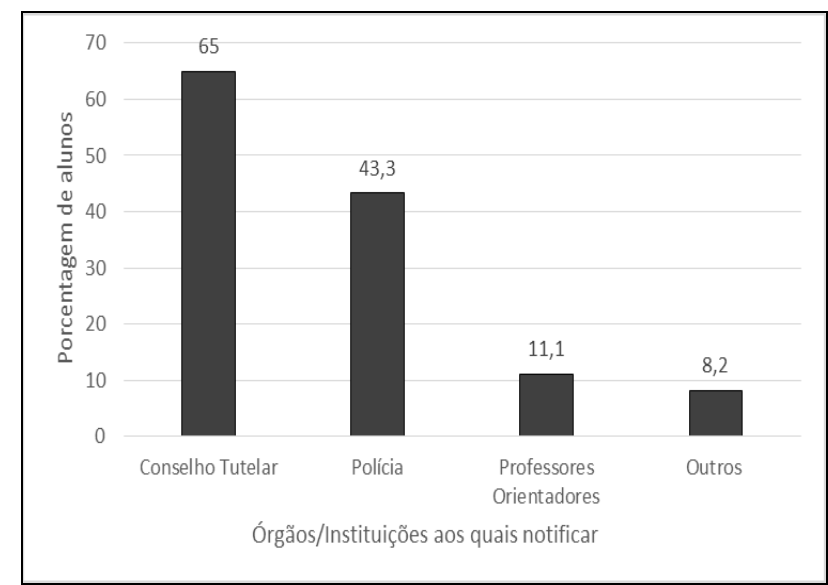

Tabela 1 - Distribuição das vivências e atitudes dos alunos de Odontologia frente a casos de abuso físico infantil $(n=195)$

\begin{tabular}{|c|c|c|}
\hline Perguntas & $\begin{array}{c}\text { Sim } \\
\text { n }(\%)\end{array}$ & $\begin{array}{c}\text { Não } \\
\text { n (\%) }\end{array}$ \\
\hline $\begin{array}{l}\text { 1-Durante seu curso de graduação você já viu algum caso suspeito de } \\
\text { abuso físico entre seus pacientes infantis? }\end{array}$ & $28(14,4)$ & $167(85,6)$ \\
\hline $\begin{array}{l}\text { 2- Você já notificou algum caso suspeito de abuso físico em criança } \\
\text { entre seus pacientes? }\end{array}$ & $5(2,6)$ & $190(97,4)$ \\
\hline $\begin{array}{l}\text { 3- Você já viu algum caso de trauma orofacial infantil, que tivesse } \\
\text { relação com abuso físico em criança, durante sua graduação? }\end{array}$ & $6(3,1)$ & $189(96,9)$ \\
\hline $\begin{array}{l}\text { 4- Você já viu algum caso suspeito de abuso físico em criança no } \\
\text { último ano? }\end{array}$ & $43(22,1)$ & $151(77,4)$ \\
\hline $\begin{array}{l}\text { 5- Você já viu algum caso comprovado de abuso físico em criança no } \\
\text { último ano? }\end{array}$ & $20(10,3)$ & $75(89,7)$ \\
\hline $\begin{array}{l}\text { 6- Você já notificou algum caso em que suspeitasse ou algum caso } \\
\text { comprovado de abuso físico em criança às autoridades no último ano? }\end{array}$ & $4(2,1)$ & $191(97,9)$ \\
\hline $\begin{array}{l}\text { 7- Você sabe a quem recorrer para fazer uma notificação diante de } \\
\text { uma suspeita ou identificação de abuso físico em criaça? }\end{array}$ & $145(74,4)$ & $50(25,6)$ \\
\hline $\begin{array}{l}\text { 8- Você tem algum telefone ou endereço de contato do órgão, } \\
\text { instituição, ou profissional responsável por receber a notificação de } \\
\text { abuso físico à criança? }\end{array}$ & $45(23,1)$ & $149(76,4)$ \\
\hline $\begin{array}{l}\text { 9- Você quer receber treinamento sobre como identificar e sobre os } \\
\text { mecanismos de notificação de casos suspeitos de abuso físico em } \\
\text { criança (ex.: cursos, oficinas)? }\end{array}$ & $175(89,7)$ & $18(9,2)$ \\
\hline $\begin{array}{l}\text { 10- Você acha que os mecanismos de identificação e notificação de } \\
\text { possíveis casos de abuso físico em crianças devem ser parte de cursos } \\
\text { de capacitação profissional? }\end{array}$ & $189(96,6)$ & $5(2,6)$ \\
\hline
\end{tabular}


Tabela 2 - Comparação das vivências e atitudes dos alunos de Odontologia, de acordo com o período do curso (n=195)

\begin{tabular}{|c|c|c|c|c|c|c|c|c|}
\hline \multirow[b]{2}{*}{ Perguntas } & \multicolumn{8}{|c|}{ Períodos do Curso } \\
\hline & & $\begin{array}{c}\mathbf{8}^{\mathbf{0}} \\
\mathrm{n}(\%)\end{array}$ & $\begin{array}{c}\mathbf{6}^{\mathbf{0}} \\
\mathrm{n}(\%)\end{array}$ & $\mathbf{p}^{*}$ & $\begin{array}{c}\mathbf{7}^{\mathbf{0}} \\
\mathrm{n}(\%)\end{array}$ & $\mathbf{p}^{*}$ & $\begin{array}{c}9^{\circ} \\
\mathrm{n}(\%)\end{array}$ & $\mathbf{p}^{*}$ \\
\hline \multirow{2}{*}{$\begin{array}{l}\text { 1.Durante a graduação você já viu algum caso } \\
\text { suspeito de abuso físico entre seus pacientes } \\
\text { infantis? }\end{array}$} & Sim & $4(9,8 \%)$ & $7(12,1 \%)$ & 1,0 & $10(18,2 \%)$ & 0,381 & $7(17,1 \%)$ & 0,519 \\
\hline & Não & $37(90,2 \%)$ & $51(87,9 \%)$ & & $45(81,8 \%)$ & & $34(82,9 \%)$ & \\
\hline \multirow{2}{*}{$\begin{array}{l}\text { 2.Você já notificou algum caso suspeito de abuso } \\
\text { físico em crianças entre seus pacientes? }\end{array}$} & Sim & $1(2,4 \%)$ & $2(3,4 \%)$ & 1,0 & $0(0,0 \%)$ & 0,427 & $2(4,9 \%)$ & 1,0 \\
\hline & Não & $40(97,6 \%)$ & $56(96,6 \%)$ & & $55(100 \%)$ & & $39(95,1 \%)$ & \\
\hline \multirow{2}{*}{$\begin{array}{l}\text { 3.Você já viu algum caso de trauma orofacial, que } \\
\text { tivesse relação com abuso físico em crianças, durante } \\
\text { a graduação? }\end{array}$} & Sim & $0(0,0 \%)$ & $1(1,7 \%)$ & 1,0 & $3(5,5 \%)$ & 0,258 & $2(4,9 \%)$ & 0,494 \\
\hline & Não & $41(100,0 \%)$ & $57(98,3 \%)$ & & $52(94,5 \%)$ & & $39(95,1 \%)$ & \\
\hline \multirow{2}{*}{$\begin{array}{l}\text { 4.Você já viu algum caso suspeito de abuso físico em } \\
\text { criança no último ano? }\end{array}$} & Sim & $7(17,1 \%)$ & $13(22,8 \%)$ & 0,614 & $13(23,6 \%)$ & 0,461 & $10(24,4 \%)$ & 0,587 \\
\hline & Não & $34(82,9 \%)$ & $44(77,2 \%)$ & & $42(76,4 \%)$ & & $31(75,6 \%)$ & \\
\hline \multirow{2}{*}{$\begin{array}{l}\text { 5.Você já viu algum caso comprovado de abuso } \\
\text { físico no último ano? }\end{array}$} & Sim & $5(12,2 \%)$ & $4(6,9 \%)$ & 0,453 & $6(10,9 \%)$ & 1,0 & $5(12,2 \%)$ & 1,0 \\
\hline & Não & $36(87,8 \%)$ & $54(93,1 \%)$ & & $49(89,1 \%)$ & & $36(87,8 \%)$ & \\
\hline \multirow{2}{*}{$\begin{array}{l}\text { 6. Você já notificou algum caso em que suspeitasse } \\
\text { ou algum caso comprovado de abuso físico em } \\
\text { criança às autoridades no último ano? }\end{array}$} & Sim & $1(2,4 \%)$ & $1(1,7 \%)$ & 1,0 & $1(2,8 \%)$ & 1,0 & $1(2,4 \%)$ & 1,0 \\
\hline & Não & $40(97,6 \%)$ & $57(98,3 \%)$ & & $54(98,2 \%)$ & & $40(97,6 \%)$ & \\
\hline \multirow{2}{*}{$\begin{array}{l}\text { 7. Você quer receber treinamento sobre como } \\
\text { identificar e sobre os mecanismos de notificação de } \\
\text { casos suspeitos de abuso físico em criança (ex.: } \\
\text { cursos, oficinas)? }\end{array}$} & Sim & $30(76,9 \%)$ & $55(94,8 \%)$ & $\mathbf{0 , 0 1 2}$ & $52(94,5 \%)$ & 0,025 & $38(92,7 \%)$ & 0,063 \\
\hline & Não & $9(23,1 \%)$ & $3(5,2 \%)$ & & $3(5,5 \%)$ & & $3(7,3 \%)$ & \\
\hline \multirow{2}{*}{$\begin{array}{l}\text { 8. Você acha que os mecanismos de identificação e } \\
\text { notificação de possíveis casos de abuso físico em } \\
\text { criança devem ser parte de cursos de capacitação } \\
\text { profissional? }\end{array}$} & Sim & $39(95,1 \%)$ & $58(100 \%)$ & 0,169 & $51(94,4 \%)$ & 1,0 & $41(100 \%)$ & 0,494 \\
\hline & Não & $2(4,9 \%)$ & $0(0,0 \%)$ & & $3(5,6 \%)$ & & $0(0,0 \%)$ & \\
\hline
\end{tabular}


As pontuações médias das autoavaliações que utilizaram escala de 0 a 10 encontram-se descritas na tabela 3. Ao realizar a comparação dessas médias, segundo os períodos, foram observadas diferenças estatísticas significantes entre os grupos. As diferenças foram evidenciadas ao considerar a capacidade de diagnosticar $(\mathrm{p}=0,022)$ e a disposição a se envolver na detecção do AFI $(p=0,011)$ (tabela 4). Por meio das comparações múltiplas observou-se que os alunos do $9^{\circ}$ período se consideram mais aptos a diagnosticar do que os do $7^{\circ}$ período $(\mathrm{p}=0,008)$ e que o grupo do $6^{\circ}$ período estava mais disposto a envolver-se na detecção do AFI do que o grupo do $8^{\circ}$ período $(\mathrm{p}=0,013)$.

Para os alunos os três principais fatores que poderiam facilitar ou encorajar os profissionais da saúde a notificarem casos suspeitos de AFI foram confidencialidade $(79,1 \%)$, segurança $(72,9 \%)$ e capacitação $(68,3 \%)$. Também foram citadas facilitação do processo de $\mathrm{NC}(48,0 \%)$ e interdisciplinaridade/ intersetorialidade $(22,0 \%)$. Apenas um aluno $(0,5 \%)$ assinalou a opção outros e três não responderam à questão. Com relação às três principais barreiras para a realização da NC destacaram-se medo, conhecimento insuficiente e falta de confidencialidade com frequência de $86,0 \%, 81,9 \%$ e $62,3 \%$, respectivamente. Também foram assinalados negligência (87, $44,8 \%)$, excesso de demanda $(13,6,7 \%)$ e outros $(1,5 \%)$. Apenas um aluno não respondeu à questão $(0,5 \%)$.

Tabela 3 - Autoavaliação: médias de respostas dos alunos de Odontologia segundo escala de 0 a 10

\begin{tabular}{|c|c|}
\hline Perguntas & Média ( $\sigma)$ \\
\hline $\begin{array}{l}\text { 1-O quanto você é capaz de reconhecer sinais e sintomas de abuso físico em } \\
\text { criança? }\end{array}$ & $5,89( \pm 1,78)$ \\
\hline $\begin{array}{l}\text { 2- O quanto você é efetivamente capaz de diagnosticar o abuso físico em } \\
\text { crianças? }\end{array}$ & $5,26( \pm 1,96)$ \\
\hline $\begin{array}{l}\text { 3- O quanto você se sente disposto a envolver-se na detecção do abuso físico } \\
\text { contra a criança? }\end{array}$ & $7,93( \pm 2,2)$ \\
\hline $\begin{array}{l}\text { 4- O quanto você acha que a sua graduação colabora para te deixar } \\
\text { preparado para o atendimento à criança? }\end{array}$ & $5,47( \pm 2,3)$ \\
\hline 5- Quanto você se sente interessado pelo atendimento à criança? & $6,78( \pm 2,51)$ \\
\hline 6- Quanto você se sente preparado para o atendimento à criança? & $6,12( \pm 1,8)$ \\
\hline $\begin{array}{l}\text { 7- Quanto você se sente interessado em cursos de educação continuada e } \\
\text { treinamentos para aprimorar o atendimento à criança? }\end{array}$ & $7,04( \pm 2,6)$ \\
\hline
\end{tabular}

$\sigma:$ desvio-padrão 
Tabela 4 - Comparação das autoavaliações (escala de 0 a 10) dos alunos de Odontologia de acordo com o período

\begin{tabular}{|c|c|c|c|c|c|c|c|c|}
\hline \multicolumn{2}{|c|}{ Período } & $\begin{array}{l}\text { É capaz de } \\
\text { reconhecer } \\
\text { sinais e } \\
\text { sintomas de } \\
\text { abuso físico } \\
\text { em criança? }\end{array}$ & $\begin{array}{l}\text { É efetivamente } \\
\text { capaz de } \\
\text { diagnosticar o } \\
\text { abuso físico em } \\
\text { criança? }\end{array}$ & $\begin{array}{l}\text { Se sente disposto } \\
\text { a envolver-se na } \\
\text { detecção do abuso } \\
\text { físico contra } \\
\text { criança? }\end{array}$ & $\begin{array}{c}\text { Quanto sua } \\
\text { graduação } \\
\text { colabora para te } \\
\text { deixar preparado } \\
\text { para o atendi- } \\
\text { mento à } \\
\text { criança? }\end{array}$ & $\begin{array}{l}\text { Quanto você } \\
\text { se sente } \\
\text { interessado } \\
\text { pelo } \\
\text { atendimento à } \\
\text { criança? }\end{array}$ & $\begin{array}{c}\text { Quanto você se } \\
\text { sente preparado } \\
\text { para o atendimento } \\
\text { à criança? }\end{array}$ & $\begin{array}{c}\text { Quanto você se sente } \\
\text { interessado em cursos } \\
\text { de educação continuada } \\
\text { e treinamentos para } \\
\text { aprimorar o atendimento } \\
\text { a crianças? }\end{array}$ \\
\hline \multirow[t]{5}{*}{$6^{\circ}}$. & $\mathbf{n}$ & 58 & 58 & 58 & 58 & 57 & 58 & 58 \\
\hline & Média $(\sigma)$ & $5,98(1,86)$ & $5,45(2,09)$ & $8,71(1,77)$ & $5,72(2,12)$ & $7,09(2,23)$ & $6,19(1,56)$ & $7,05(2,73)$ \\
\hline & Variância & 3,491 & 4,392 & 3,158 & 4,51 & 5,01 & 2,43 & 7,45 \\
\hline & Máximo & 10 & 10 & 10 & 10 & 10 & 10 & 10 \\
\hline & Mínimo & 1 & 1 & 3 & 0 & 1 & 3 & 1 \\
\hline \multirow[t]{5}{*}{$7^{\circ}$} & $\mathbf{n}$ & 54 & 52 & 55 & 55 & 55 & 55 & 55 \\
\hline & Média $(\sigma)$ & $5,46(2,03)$ & $4,87(1,94)$ & $7,62(2,40)$ & $5,25(2,37)$ & $6,25(2,66)$ & $5,93(1,93)$ & $6,75(2,88)$ \\
\hline & Variância & 4,140 & 3,76 & 5,759 & 5,63 & 7,08 & 3,73 & 8,34 \\
\hline & Máximo & 10 & 10 & 10 & 10 & 10 & 10 & 10 \\
\hline & Mínimo & 0 & 0 & 1 & 1 & 1 & 2 & 1 \\
\hline \multirow[t]{5}{*}{$8^{\circ}$} & $\mathbf{n}$ & 41 & 41 & 41 & 41 & 41 & 41 & 41 \\
\hline & Média $(\sigma)$ & $5,83(1,51)$ & $4,88(1,88)$ & $6,63(2,33)$ & $5,98(2,27)$ & $7,17(2,51)$ & $6,20(1,91)$ & $7,44(2,31)$ \\
\hline & Variância & 2,295 & 3,56 & 5,438 & 5,17 & 6,34 & 3,66 & 5,35 \\
\hline & Máximo & 9 & 8 & 10 & 10 & 10 & 9 & 10 \\
\hline & Mínimo & 3 & 1 & 2 & 1 & 1 & 1 & 1 \\
\hline \multirow[t]{5}{*}{$9^{\circ}$} & n & 41 & 41 & 41 & 41 & 41 & 41 & 41 \\
\hline & Média $(\sigma)$ & $6,37(1,44)$ & $5,85(1,74)$ & $7,83(2,14)$ & $4,88(2,37)$ & $6,68(2,62)$ & $6,22(2,01)$ & $7,00(2,57)$ \\
\hline & Variância & 2,088 & 3,02 & 4,595 & 5,66 & 6,87 & 4,07 & 6,65 \\
\hline & Máximo & 10 & 10 & 10 & 8 & 10 & 9 & 10 \\
\hline & Mínimo & 3 & 2 & 3 & 0 & 1 & 1 & 1 \\
\hline \multicolumn{2}{|c|}{ Valor de p $^{*}$} & 0,136 & 0,022 & 0,011 & 0,175 & 0,301 & 0,706 & 0,789 \\
\hline
\end{tabular}

* Teste de Kruskal-Wallis: significância de 5\%; $\sigma$ desvio-padrão 


\section{DISCUSSÃO}

No presente estudo, a maioria dos estudantes relatou não ter se deparado com casos suspeitos de AFI ou de traumas orofaciais que pudessem ter relação com maus-tratos infantis, assim como não notificou às autoridades durante a graduação. Ademais, alegou saber o órgão ou instituição ao qual recorrer, citando em primeiro lugar o Conselho Tutelar. Os alunos, em sua quase totalidade, creem que a abordagem do tema deva fazer parte da sua formação profissional.

Quanto à experiência vivenciada pelos alunos, observou-se que a maioria não viu casos de AFI durante a graduação. A existência de uma possível subnotificação é um fator a ser considerado, pois segundo os resultados encontrados, o percentual de alunos que notificou é inferior ao daqueles que viram casos suspeitos entre seus pacientes infantis. Esses resultados corroboram estudos realizados com cirurgiões-dentistas, nos quais se observou que o percentual daqueles que notificaram às autoridades sempre era inferior ao daqueles que suspeitaram de $\mathrm{AFI}^{11,15,20}$ e com estudos conduzidos com alunos, nos quais se observou que a maioria nunca suspeitou de abuso físico entre seus pacientes ${ }^{17,21}$. Além disso, os dados do presente estudo apontam que o número de casos observados no último ano supera os casos identificados na prática clínica, fato que pode remeter a outras vivências e experiências do aluno.

As médias obtidas para a capacidade dos graduandos em reconhecer os principais sinais do AFI e para o quanto são efetivamente capazes de diagnosticar casos suspeitos foram similares às encontradas em estudo conduzido com cirurgiões-dentistas, uma vez que os autores encontraram média 6,0 para o quanto os profissionais se sentem capazes em reconhecer sinais e sintomas e 5,0 para o quanto se sentem aptos a diagnosticar ${ }^{15}$. Lazenbatt e Freeman $(2006)^{11}$ ao compararem o conhecimento, experiência e atitudes dos profissionais da atenção básica, observaram que os cirurgiõesdentistas apresentaram médias menores em relação à capacidade de reconhecer sinais e sintomas $(4,21)$ e efetividade em diagnosticar o AFI $(3,27)$, quando comparados a médicos e enfermeiros. Resultados similares também foram encontrados em estudos realizados com alunos e profissionais, nos quais observou-se conhecimento e capacidade diagnóstica deficientes $^{17,22}$. Azevedo et al. $(2012)^{20}$ e Matos et al. $(2013)^{21}$ encontraram resultados distintos aos do presente estudo, pois um percentual de entrevistados superior a 70,0\% considerava-se apto a diagnosticar crianças e adolescentes vítimas de maus-tratos.

No presente trabalho, os alunos do $6^{\circ}$ período apresentaram maior interesse em receber treinamentos sobre o AFI. Os resultados encontrados chamam a atenção, pois a literatura analisada evidencia que o conhecimento e interesse dos alunos do último ano é superior ao dos alunos de períodos precedentes ${ }^{9,19,25}$. Nesse sentido, o maior interesse desses alunos pode relacionar-se ao recente contato com a disciplina "Legislação e Ética Odontológica" e à sua introdução à clínica de Odontopediatria.

Apesar dos alunos do $9^{\circ}$ período, da presente pesquisa, sentirem-se mais capazes de diagnosticar os sinais e sintomas do AFI em comparação aos do $7^{\circ}$ período, observa-se na literatura que o conhecimento dos alunos sobre os principais sinais diagnósticos de AFI tem sido apontado como baixo, independentemente do grau de instrução ${ }^{18}$. Este fato pode estar atrelado à baixa vivência do aluno envolvendo 
casos de traumas orofaciais associados ao AFI, o que foi evidenciado neste estudo e corrobora os achados de Marengo et al. $(2013)^{15}$, em que $82,5 \%$ dos profissionais não viram casos de trauma orofacial associado a maus-tratos nos últimos seis meses. Além disso, outros relatos evidenciam que o conhecimento acerca do tema não é adequado, pois um percentual considerável de alunos e profissionais não estava ciente da alta prevalência de tais lesões, bem como não sabiam qual a região do organismo mais afetada em casos de violência infantil $^{18,19,23}$.

Quanto às responsabilidades legais e éticas relacionadas ao tema, observou-se que $74,4 \%$ dos entrevistados alegou saber o órgão ao qual recorrer para realizar uma NC. Esse resultado diverge da maioria dos estudos analisados, nos quais um percentual considerável de entrevistados desconhecia a quem notificar ${ }^{17-19,22}$. Lazenbatt e Freeman $(2006)^{11}$, observaram que $74,0 \%$ dos profissionais relatou saber algum mecanismo de $\mathrm{NC}$, porém dentre os três grupos analisados, os dentistas apresentaram o pior resultado.

No presente trabalho, o Conselho Tutelar seria o primeiro órgão ao qual os alunos recorreriam, seguido pela polícia. Esse resultado está em concordância com as diretrizes estabelecidas pelo Estatuto da Criança e do Adolescente e apresenta similaridade a diversos estudos $^{9,21,23}$. Ressalta-se que diante de casos de suspeitas de maus-tratos infantis, o profissional da saúde realize o atendimento de urgência e notifique aos conselhos tutelares, por meio de oficio ou telefonema. $\mathrm{Na}$ falta deste órgão, recomenda-se notificar ao juizado da infância e da juventude, aos órgãos de proteção à criança, ou ainda reportar o caso às autoridades policiais e solicitar o encaminhamento para o exame de corpo de delito ${ }^{13,21}$. O profissional que deixar de comunicar às autoridades casos de AFI que vierem ao seu conhecimento pode ser penalizado com multa de três a vinte saláriosmínimos ${ }^{16,21}$. Ressalta-se que o Conselho Federal de Odontologia estabelece como dever do cirurgião-dentista zelar pela saúde e dignidade do paciente ${ }^{14}$, no entanto não há uma especificação clara no Código de Ética Profissional sobre as condutas a serem tomadas pelo profissional ao se deparar com uma suspeita de maus-tratos. Portanto, é necessário que sejam estabelecidas orientações sobre a conduta a ser tomada ${ }^{21}$.

Um dos principais problemas que permeiam o AFI é a subnotificação ${ }^{6}$, por isso compreender quais são os empecilhos para que os profissionais da saúde notifiquem os casos às autoridades é fundamental. No presente estudo, os alunos consideraram o medo, o conhecimento insuficiente e a falta de confidencialidade como as principais barreiras enfrentadas pelos profissionais da saúde, concordando com os achados de Lazenbatt e Freeman $(2006)^{11}$. O medo tem sido apontado como um importante fator, pois profissionais relataram que caso notificassem suspeitas de abuso, o fariam de modo anônimo ${ }^{23}$. Outros fatores como receio de um diagnóstico incorreto, não saber a quem denunciar e não saber o que fazer quando confrontados, também foram apontados na literatura ${ }^{18,19,22,23}$.

A abordagem do tema de forma adequada durante a graduação é de extrema importância para a formação do estudante. Um treinamento eficaz permitirá ao futuro profissional saber diagnosticar e adotar condutas assertivas frente a possíveis casos de $\mathrm{AFI}^{16}$. Al-Jundi et al. $(2010)^{18}$ observaram que mais da metade dos alunos entrevistados considerou a Universidade como o local adequado para receber informação sobre o tema, bem como acredita não haver 
recebido treinamento formal suficiente para reconhecer e notificar casos de AFI. No presente estudo, observou-se que os alunos não perceberam a graduação como colaboradora em seu preparo para o atendimento à criança, apontando quase em totalidade, a necessidade de incluir treinamentos sobre o tema em cursos de capacitação profissional. Essa opinião também foi expressada em diversos estudos nos quais alunos e profissionais da saúde apontaram a necessidade de receber capacitação sobre o assunto $^{11,15,22,26}$.

Neste trabalho, obtiveram-se médias semelhantes para a disposição do aluno em envolver-se na detecção do AFI, bem como interesse em cursos de capacitação sobre o tema. Em contrapartida, Marengo et al. (2013) encontraram média máxima no que concerne à disposição dos profissionais em envolver-se na detecção de casos (10,0). Por outro lado, Lazenbatt e Freeman (2006) ${ }^{11}$ observaram que dentre médicos, enfermeiros e dentistas da atenção primária à saúde, os últimos além de apresentarem baixo conhecimento apresentaram ainda, baixo interesse em envolver-se na detecção de AFI.

A necessidade de reformulação dos projetos curriculares e a elaboração de novas intervenções pedagógicas tem se mostrado cada vez mais importante. Moura et al. $(2015)^{23}$ expuseram que $60,0 \%$ dos alunos de Odontologia do $5^{\circ}$ ano, relataram que o assunto foi abordado durante a graduação. De modo similar, Al-Jundi et al. $(2010)^{18}$ verificaram que a maioria dos alunos alegou haver lido sobre o tema, porém, ainda assim, o conhecimento foi deficiente. Jordan et al. $(2012)^{19}$ expuseram que apenas $60,0 \%$ dos alunos relataram realmente haver sentido deparar-se com o assunto durante a graduação. Segundo os autores, tal achado pode dever-se ao fato do tema ser abordado em disciplinas eletivas sendo, portanto, frequentadas apenas por alguns alunos. Thomas et al. $(2006)^{17}$ observaram que $100 \%$ dos alunos de Odontologia relatou haver lido sobre o tema, sendo que a maioria o fez em aulas teóricas. Observou-se que somente leituras teóricas não preparam adequadamente o futuro cirurgiãodentista para a resolução de problemas ${ }^{18}$. Para superar o panorama apresentado, propõe-se o uso da Teoria de Aprendizagem Experimental, pois a mesma permite ao aluno absorver o conteúdo de forma teórica e realizar uma análise crítica, no intuito de desenvolver novas habilidades e comportamentos para enfrentar situações diversas $^{18}$.

A limitação deste estudo atrela-se ao fato de ter sido realizado em uma única instituição de ensino privada. No entanto, é o primeiro estudo que visa avaliar as experiências e as atitudes de alunos de Odontologia, utilizando um questionário previamente validado, em Belo Horizonte, Minas Gerais ${ }^{24}$. Apesar da limitação, a pesquisa se adequa à realidade local e possui validade interna, permitindo avaliar o conhecimento e o preparo do aluno a respeito do tema na amostra envolvida. Nesse sentido, contribui para a sugestão de melhorias curriculares a fim de conscientizar o futuro profissional quanto à importância do problema e prepará-lo para atuar frente a possíveis casos de AFI.

\section{CONCLUSÕES}

A maioria dos alunos não viu ou notificou casos suspeitos de AFI, bem como traumas orofaciais que pudessem estar relacionados. Os alunos não se sentiam preparados para reconhecer os principais sinais e sintomas do AFI, porém manifestaram interesse em receber treinamentos sobre o tema e souberam a quem recorrer no caso de NC. Percebeu-se que a 
graduação precisa melhorar sua colaboração no preparo do aluno para o atendimento de casos de AFI, sugerindo a necessidade do desenvolvimento de estratégias pedagógicas que melhorem a abordagem do tema.

\section{ABSTRACT \\ Physical child abuse: experiences and attitudes of Dental students}

The purpose of this study was to verify the experiences vivências and attitudes of Dental undergraduate students, facing physical child abuse cases. This study was carried out in 2016, with a representative sample $(\mathrm{N}=195)$ of junior and senior undergraduate students from a private education institution. The data were collected through a self-administered questionnaire, validated in Portuguese. In the statistical analysis, a descriptive analysis and comparative were performed with Chi-square, Kruskal-Wallis tests, and multiple comparisons. The majority of the students did not identify physical child abuse cases $(85,6 \%)$, did not perform reports $(97,4 \%)$ and claims to know the proper entities to which notify $(74,4 \%)$, being mentioned the Tutelary Council $(65,0 \%)$. In a 0 to 10 scale, the undergraduate program collaborates with an average of 5.47 for students preparation for care for a child victim of physical abuse. In this regard, $89,7 \%$ of the students states the interest in receiving training regarding the theme. A significant difference was observed among students in regard to the effectiveness of recognizing the main signs and symptoms of physical child abuse and the interest in training regarding the theme. Based on the results it is suggested the need for greater emphasis on this theme during the course, aiming at preparing the future professional to deal with cases of physical abuse of children.

Descriptors: Child Abuse. Dentistry. Students.

\section{REFERÊNCIAS}

1. World Health Organization. Report of the consultation on child abuse prevention, 29-
31 March 1999. Geneva, World Health Organization, 1999. [Acesso em 09 jan. 2017]. Disponível em: http://apps.who. int/iris/handle/10665/65900.

2. World Health Organization. Child maltreatment. Geneva, Switzerland: World Health Organization. 2014.

3. Garbin CAS, Guimarães e Queiroz APD; Rovida TAS, Saliba O. A violência familiar sofrida na infância: uma investigação com adolescentes. Psicol Rev. 2012; 18(1):10718.

4. Reicheinhem ME, Souza ER, Moraes CL, Mello Joge MH, Silva CMFP, Minayo MCS. Violência e lesões no Brasil: efeitos, avanços alcançados e desafios futuros. Lancet. 2011; 6736(11)75-89.

5. World Health Organization (WHO). Preventing child maltreatment: a guide to taking action and generating evidence. Suiça: World Health Organization. 2006. [Acesso em 09 jan. 2017]. Disponível em: http://www.who.int/violence_injury_prevent ion/publications/violence/child_maltreatmen t/en/.

6. U.S. Department of Health \& Human Services. Child Maltreatment 2010. Washington: U.S. Department of Health \& Human Services; 2013. [Acesso em 09 jan. 2017]. Disponível em: https://www.acf. hhs.gov/sites/default/files/cb/cm2013.pdf.

7. Cavalcanti AL. Prevalence and characteristics of injuries to the head and orofacial region in physically abused children and adolescents - a retrospective study in a city of the Northeast of Brazil. Dent Traumatol. 2010;26:149-53.

8. Dalledone M, de Paola APB, Correr GM, Pizzatto E, de Souza JF, Losso, EM. Child abuse: perception and knowledge by Public Health Dentistry teams in Brazil. Braz J Oral 
Sci. 2015;14(3):224-9.

9. Paulino de Souza GF, Carvalho MMP, Granville-Garcia AF, Gomes MNC, Ferreira JMS. Conhecimento de acadêmicos em odontologia sobre maus-tratos infantis. Odonto. 2012;20(40):101-8.

10. Garbin CAS, Dias IA, Rovida TAS, Garbin AJI. Desafios do profissional de saúde na notificação da violência: obrigatoriedade, efetivação e encaminhamento. Ciênc Saúde Coletiva. 2015;20(6):1879-90.

11. Lazenbatti A, Freeman R. Recognizing and reporting child physical abuse: A survey of primary healthcare professionals. J Adv Nurs. 2006; 56(3):227-36.

12. Moreira GAR; Rolim ACA; Saintrain MVL; Vieira LJES. Atuação do cirurgião-dentista na identificação de maus-tratos contra crianças e adolescentes na atenção primária. Saúde Debate. 2015; 39: 257-67.

13. Brasil. Estatuto da Criança e do Adolescente. Lei No 8.069 de 13 de Julho de 1990. Dispõe sobre o Estatuto da Criança e do Adolescente e dá outras providências. [Acesso em 13 jan. 2017]. Disponível em: http://www.planalto.gov.br/ccivil_03/ LEIS /L8069.htm.

14. Conselho Federal de Odontologia. Código de Ética Odontológica. [Acesso em 13 jan. 2017]. Disponível em: http://cfo.org.br.

15. Marengo G, Paola APB, Ferreira FM, Pizzatto E, Correr GM, Losso EM. Child abuse: validation of a questionnaire translated into Brazilian Portuguese. Braz Oral Res. 2013; 27(2):163-8.

16. Silva Junior MF, Pagel MD, Campos DMKS, Miotto MHMB. Conhecimento de acadêmicos de Odontologia sobre maustratos infantis. Arq Odontol. 2015; 51(3):138-44.

17. Thomas JE, Straffon L, Inglehart MR. Child abuse and neglect: dental and dental hygiene students' educational experiences and knowledge. J Dent Educ. 2006;70(5):55865.

18. Al-Jundi SHS, Zawaideh, FI; Al-Rawi, MH. Jordanian Dental students' knowledge and attitudes in regard to child physical abuse. $\mathbf{J}$ Dent Educ. 2010; 74(10):1159-65.

19. Jordan A, Welbury RR, Tiljak, MK. Croatian Dental Students' educational experiences and knowledge in regard to child abuse and neglect. J Dent Educ. 2012; 76(11):1512-9.

20. Azevedo MS, Goettems ML, Brito A, Possebon AP, Domingues, J, Demarco, FF, Torriani, DD. Child maltreatment: a survey of dentists in southern Brazil. Braz Oral Res. 2012; 26(1):5-11.

21. Mattos FZ, Borges AH, Mamede Neto, I, Rezende CD, Silva KL, Pedro FLM, Porto AN. Avaliação do conhecimento dos alunos de graduação em odontologia $x$ cirurgião dentista no diagnóstico de maus-tratos a crianças. Rev Odontol Bras Central. 2013; 22(63):153-7.

22. Mogaddam M, Kamal I, Merdad L. Alamoudic N. Knowledge, attitudes, and behaviors of dentists regarding child physical abuse in Jeddah, Saudi Arabia. Child Abuse \& Neglect. 2016; 54: 43-56.

23. Moura AR, Amorim A, Proença L, Milagre V. Dentists and undergraduate dental students require more information relating to child abuse. Medical Express. 2015;2(2):14.

24. Silva-Oliveira F, Ferreira e Ferreira E, Mattos FF, Ribeiro MTF, Cota LOM, Vale MP, Zarzar PM. Adaptação transcultural e reprodutibilidade de questionários para avaliação de conhecimento de profissionais de saúde frente a casos de abuso físico 
infantil. Ciência \& Saúde Coletiva. 26. Silva, KBG; Cavalcanti, AFC; Cavalcanti, 2014;19(3):917-29.

AL. Child abuse: knowledge and actions undertaken by dentists of the Family Health Strategy in Guarabira - PB, Brazil. maus tratos infantis pelos estudantes de Odontologia da UFPB. Int J Dent. 2011; 10(4):234-41.

REFACS. 2016; 5(Supl.1):108-17.

Correspondência para:

Profa. Camilla Aparecida Silva de Oliveira

e-mail: camillaaparecidasol@gmail.com

Rua Dr. Ari Teixeira da Costa, 377

33025-010 -Esplanada - Santa Luzia/MG 